Full length article

\title{
Listed for sale: Analyzing data on fentanyl, fentanyl analogs and other novel synthetic opioids on one cryptomarket
}

\author{
Francois R. Lamy ${ }^{\mathrm{a}, *}$, Raminta Daniulaityte ${ }^{\mathrm{b}}$, Monica J. Barratt ${ }^{\mathrm{c}, \mathrm{d}}$, Usha Lokala ${ }^{\mathrm{e}}$, Amit Sheth ${ }^{\mathrm{f}}$, \\ Robert G. Carlson ${ }^{g}$ \\ a Department of Society and Health, Faculty of Social Sciences and Humanities, Mahidol University, Salaya, Thailand \\ ${ }^{\mathrm{b}}$ College of Health Solutions, Arizona State University, Phoenix, AZ, United States \\ ${ }^{\mathrm{c}}$ Social and Global Studies Centre, RMIT University, Melbourne, VIC, Australia \\ ${ }^{\mathrm{d}}$ National Drug and Alcohol Research Centre, UNSW Sydney, NSW, Australia \\ ${ }^{\mathrm{e}}$ Kno.e.sis Center, Department of Computer Science, Wright State University, Dayton, OH, United States \\ ${ }^{\mathrm{f}}$ Artificial Intelligence Center, University of South Carolina, Columbia, SC, United States \\ ${ }^{\mathrm{g}}$ Center for Interventions, Treatment, and Addictions Research, Department of Population and Public Health Sciences, Wright State University, Dayton, OH, United States
}

\section{A R T I C L E I N F O}

\section{Keywords:}

Cryptomarkets

Darknet markets

Fentanyl

Fentanyl analogs

Synthetic opioids

\begin{abstract}
A B S T R A C T
Background: The United States is facing a "triple wave" epidemic fueled by novel synthetic opioids. Cryptomarkets, anonymous marketplaces located on the deep web, play an increasingly important role in the distribution of illicit substances. This article presents the data collected and processed by the eDarkTrends platform concerning the availability trends of novel synthetic opioids listed on one cryptomarket.

Methods: Listings from the DreamMarket cryptomarket "Opioids" and "Research Chemicals" sections were collected between March 2018 and January 2019. Collected data were processed using eDarkTrends Named Entity Recognition algorithm to identify opioid drugs, and to analyze their availability trends in terms of frequency of listings, available average weights, average prices, and geographic indicators of shipment origin and destination information.

Results: 95,011 opioid-related listings were collected through 26 crawling sessions. 33 novel synthetic opioids were identified in $3.3 \%$ of the collected listings. $44.7 \%$ of these listings advertised fentanyl (pharmaceutical and non-pharmaceutical) or fentanyl analogs for an average of $2.8 \mathrm{kgs}$ per crawl. "Synthetic heroin" accounted for $33.2 \%$ of novel synthetic opioid listings for an average $1.1 \mathrm{kgs}$ per crawl with $97.7 \%$ of listings advertised as shipped from Canada. Other novel synthetic opioids (e.g., U-47,700, AP-237) represented $22 \%$ of these listings for an average of $6.1 \mathrm{kgs}$ per crawl with $97.2 \%$ of listings advertised as shipped from China.

Conclusions: Our data indicate consistent availability of a wide variety of novel synthetic opioids both in retail and wholesale-level amounts. Identification of new substances highlights the value of cryptomarket data for early warning systems of emerging substance use trends.
\end{abstract}

\section{Introduction}

The United States is experiencing the worst opioid overdose epidemic in its history. The first wave of the opioid crisis is associated with prescription opioids misuse. It was fueled by the increased volume of opioid prescribing, including by general practitioners, that could be traced back to the recognition of pain as the "fifth vital sign," increased concerns about the under-treatment of pain, and more aggressive marketing and distribution strategies employed by pharmaceutical companies (Van Zee, 2009; Ciccarone, 2019). From the mid 1990s to early 2010s, the diversion and misuse of pharmaceutical opioids caused a steady increase in the number of pharmaceutical opioid-related overdose deaths (Paulozzi et al., 2006; Hall et al., 2008) as well as an increase in the prevalence of opioid use disorder (Compton and Volkow, 2006). The second wave of the opioid crisis was marked by the increases in heroin use, as growing numbers of individuals who abused pharmaceutical opioids started transitioning to heroin, a more potent, plentiful and less costly alternative to illicit pain pills (Carlson et al., 2016; Cicero et al., 2014; Mars et al., 2014; Unick et al., 2014, 2013). Emerging data suggest that some of the measures that were designed to curb the availability of pharmaceutical opioids, might have inadvertently accelerated transition to heroin use among individuals who

\footnotetext{
* Corresponding author.

E-mail address: francois.lam@mahidol.edu (F.R. Lamy).
} 
were dependent on pharmaceutical opioids (Castillo-Carniglia et al., 2019). Finally, since 2013-2014, novel synthetic opioids, such as illicitly manufactured fentanyl, fentanyl analogs (i.e., substances sharing similar chemical structure and action as fentanyl) and other novel synthetic opioids (e.g., U-47,700, MT-45) have emerged in the drug market creating what has been called a "third wave" of the opioid epidemic in the US (Ciccarone, 2019; Jones et al., 2018) and exacerbating the opioid crisis even further.

In the U.S, novel synthetic opioids were responsible for $30.5 \%$ (n = 74,409 ) of all opioid-related overdose deaths that occurred nationally between 2010 and 2017 (Hedegaard et al., 2018). The negative impacts in some of the Northeastern and Midwestern communities were even more profound (Pardo et al., 2019). For example, in Montgomery County, Ohio, about $90 \%$ of all unintentional overdose deaths that occurred in 2016 and 2017 tested positive for novel synthetic opioids (Daniulaityte et al., 2017a,b, 2019).

Novel synthetic opioids are a part of the larger group of new psychoactive substances defined by the United Nations Office on Drugs and Crime (UNODC) as "substances of abuse, either in a pure form or a preparation, that are not controlled by the 1961 Single Convention on Narcotic Drugs or the 1971 Convention on Psychotropic Substances, but which may pose a public health threat." Between 2010 and 2019, the European Monitoring Centre for Drug and Drug Addiction (EMCDDA) identified 49 novel synthetic opioids in the European drug markets (EMCDDA, 2019). Most of these substances were not "new" per se, but rather, a resurgence of substances from older biomedical literature with limited information on their side effects (Baumann et al., 2018). Although fentanyl was part of the substances controlled under the 1961 convention, and has a long history of medical use in a variety of pharmaceutical forms (e.g., Duragesic transdermal system), it is included under the label of novel synthetic opioid because current increases do not involve pharmaceutical fentanyl, but are associated with non-pharmaceutical fentanyl that is illicitly produced in clandestine laboratories. It also reflects the actual position of the Drug Enforcement Agency (DEA), which considers fentanyl as the "most prevalent and most significant synthetic opioid threat in the United States" (DEA, 2018a,b).

There is a growing body of evidence showing that darknet markets, also known as cryptomarkets, play an increasingly important role in the distribution of illicit substances and goods in Western countries (Dolliver and Kuhns, 2016; Kruithof et al., 2016a, b), despite recent law enforcement operations that have dismantled several darknet markets (Madore, 2019). In contrast to the "surface web," the "deep web" is a section of the Internet where websites or databases are not listed by search engines such as Google, Bing or Yahoo. It encompasses all private data accessible via the Internet and represents approximately $96 \%$ of the total web. The "darknet" is a small subsection of the deep web that can only be accessed by using an anonymizing browser (e.g., The Onion Router (Tor) or Invisible Internet Project (I2P)) providing encrypted communication and a decentralized network structure (Aldridge and Décary-Hétu, 2016a,b; Barratt et al., 2018). Cryptomarkets are online marketplaces that function within the darknet, using cryptocurrencies (e.g., Bitcoin, Monero, Litecoin) and advanced encryption techniques to offer anonymity to vendors and consumers trading for illegal goods or services (Barratt and Aldridge, 2016). Over $60 \%$ of the listings on cryptomarket are dedicated to pharmaceutical and/or illicitly produced psychoactive substances (i.e., pharmaceuticals, drug-related chemicals or illicit drugs) (Europol and EMCDDA, 2017).

Prior studies have monitored cryptomarkets to identify emerging NPS and other psychoactive drugs by evaluating the amount of substances being supplied, drug prices, number of sellers, seller revenue, number of cryptomarkets, and country-specific information (Dolliver, 2015; Kruithof et al., 2016a,b; Van Buskirk et al., 2016). A recent statistical bulletin described the overall amount, price and physical forms of fentanyl available on six cryptomarkets over a 51-day period in the beginning of 2019 (Ball et al., 2019). However, information regarding the origin and type of these novel synthetic opioids are needed to characterize cryptomarket data related to specific types of novel synthetic opioids, such as specific types of fentanyl analogs and other novel synthetic opioids. To establish timely and effective policy and intervention responses to the opioid crisis in the U.S., epidemiological monitoring systems need to be able to rapidly identify shifts in availability trends of specific novel synthetic opioid products and alert policy makers about emerging new substances. This study builds on the eDarkTrends project that was developed to collect and process cryptomarket data on fentanyl, fentanyl analogs and other novel synthetic opioids. The overall aims of this paper are to present data collected from Dream Market over 10 months, focusing on the amounts of drugs offered for sale (in terms of number of listings and total weight available for purchase), prices, and information on distribution patterns in terms of the countries listed as shipment origin and destination.

\section{Methods}

\subsection{Data collection}

eDarkTrends, a semi-automated platform, was developed to monitor listings of fentanyl, fentanyl analogs, and other novel synthetic opioids on cryptomarkets to assess availability trends and identify emerging substances. The data presented in this paper were collected from the DreamMarket cryptomarket and covered a nearly one-year time period from March 2018 to January 2019, until DreamMarket was shut down in February 2019 (Madore, 2019). At that time, DreamMarket was the largest existing cryptomarket with over 60,000 listings for drugs (Knight, 2019). Although it established a ban on fentanyl and fentanyl analog listings in May of 2018 (Ball et al., 2019), data collection was maintained as the DreamMarket remained the biggest cryptomarket advertising thousands of other illicit synthetic opioids, and some vendors continued to sell fentanyl-type drugs under other names.

Data were collected using a custom eDarkTrends web crawler developed and maintained by the research team at the Kno.e.sis Center (fourth author U.L.). A crawler is an automated script that systematically collects all the information contained on the selected websites or their sub-sections. The eDarkTrends web crawler targeted the "Opioids" and "Research Chemicals (RC's)" sections of DreamMarket and excluded other sections. Crawler's outputs were raw HyperText Markup Language files (HTML) of drug advertisements with image source attributes removed. These raw HTML files contained the following information: product listing, vendor pseudonym, vendor number of sales and level of trust, information about the product provided by the vendor, price (Bitcoin and US\$), country/region of shipment origin, potential shipment destination country/region, security measures concerning transactions, terms and conditions, and reviews from previous buyers. Data extraction, storage and access procedures followed strict security measures reviewed and approved by the Wright State University's Information Security Office.

Data were collected at 26 time points. Although initial plans included data collection on a more frequent basis, the eDarkTrends platform experienced difficulties in completing more frequent crawls because of the technical challenges and extreme volatility of cryptomarket environments. For example, DreamMarket was not always active due to maintenance or because of DDoS (Distributed Denial of Service) attacks that aim to overload servers with requests to disrupt its normal functioning.

\subsection{Data processing}

Extracted data were processed to identify relevant drug mentions using the eDarkTrends-dedicated Named Entity Recognition (NER) algorithm developed by the first author (more details in Lokala et al., 2019). The NER algorithm was developed in the Python programming 
language (van Rossum, 1990) and integrated three key components: (1) the Natural Language ToolKit (NLTK) library was used to curate and process text segments from crawled data (Bird et al., 2009); (2) the Drug Abuse Ontology (DAO) that functions as a domain-specific conceptual framework for interconnecting sets (named "classes") of drugfocused lexicons to provide a list of terms to be identified (Cameron et al., 2013; Daniulaityte et al., 2017a,b; Lamy et al., 2017), and; (3) Regular Expressions (i.e., a sequence of symbols and characters forming a pattern to be searched within a text or sentence) built on the selected entities populating the DAO to capture objects of interest.

The Drug Abuse Ontology (DAO) was developed by the research team building on our prior work on web-based analytics for substance use epidemiology research (Cameron et al., 2013; Daniulaityte et al., 2015; Lamy et al., 2017). The DAO was created using Protégé software (Musen, 2015) and includes a comprehensive list of psychoactive substances based on available resources (e.g., Drug Enforcement Administration, National Institute on Drug Abuse, European Monitoring Centre for Drugs and Drug Addiction), prior research (e.g., Daniulaityte et al., 2015; Lamy et al., 2017), and preliminary examination of cryptomarket data. The DAO includes names of psychoactive substances (e.g., heroin, fentanyl, acetylfentanyl) including synthetic substances (e.g., U-48,800, MT-45), brand and generic denominations of pharmaceutical drugs (e.g., Fentora, Subutex) and slang terms (e.g., china white, oxy, fent). It also contains information regarding the route of administration (e.g., transdermal, IV), unit of dosage (e.g., gr, kg, ml, films), physical forms (e.g., powder, patch, drop), and drug effects (e.g., euphoria, pain control).

The eDarkTrends NER algorithm was designed to identify and group opioid drug mentions into higher-level classes (e.g., heroin, pharmaceutical fentanyl, non-pharmaceutical fentanyl). These classes included sub-classes to identify specific types of fentanyl analogs and other drugs. For example, the fentanyl analog class included a list of 51 fentanyl analog and precursor names (e.g., carfentanyl, acetylfentanyl), and other novel synthetic opioid class included a list of 17 compounds (e.g., U-47,700, AP-237) (see Table 1). Entities that were not recognized by the NER algorithm were grouped into a separate "Unidentified" class.

For the fentanyl-type drug class, the eDarkTrends NER algorithm identified both pharmaceutical and non-pharmaceutical fentanyl. Listings that mentioned pharmaceutical fentanyl brand names (e.g., Duragesic, Actiq, Sublimaze) or standard pharmaceutical forms of administration (e.g., transdermal system, lollipop, spray) were classified as pharmaceutical fentanyl (e.g., "Subsys Sublingual Fentanyl Spray $200 \mathrm{mcg}$ Pharmacy"). Fentanyl in powder form or other non- pharmaceutical forms was classified as non-pharmaceutical fentanyl (e.g., "Fentanyl $\mathrm{HCl}$ crystalls pure $98 \% 1 \mathrm{~g}$ "). The NER was also developed to correctly identify misspellings, abbreviations and slang terminology for fentanyl analogs and other novel synthetic opioids (e.g., carfentanyl as carfentanil; 3-MMAF as 3-methylmethoxyacetylfentanyl; butyrylfentanyl as butyrentanyl).

To minimize classification errors, the following strategies were used for more ambiguous drug listing scenarios. Listings for oxycodone "pressed pills" containing fentanyl (e.g., "QTY: 50 Oxycodone $30 \mathrm{mg}$ A215 FENTANYL PRESSED") were categorized as non-pharmaceutical fentanyl under a separate "Oxycodone pills with fentanyl" subcategory. Listings offering sale of "China White" with a mention of fentanyl or fentanyl analogs (e.g., "This listing is for synthetic heroin also known as china white. This is a mix of Furanyl-Fentanyl and Pharma grade mannitol professionally mixed in a mixer") were classified as nonpharmaceutical fentanyl or fentanyl analog posts. Although slang term "China White" is sometime used to refer to fentanyl that is sold as heroin (Martin et al., 1991; Ciccarone et al., 2017), but it can also refer to heroin products (Ciccarone et al., 2017). China White listings without any mention of another novel synthetic opioids were not classified as belonging to any of the novel synthetic opioid categories. "Synthetic heroin" listings lacked sufficient information to classify them together with non-pharmaceutical fentanyl, fentanyl analogs or other novel synthetic opioids, and thus they are presented as a separate, more ambiguous category. However, there is evidence to suggest that the term "synthetic heroin" is used to refer to fentanyl and/or other fentanyl analogs mixed with or sold as heroin in lay and popular media terminology (Ciccarone et al., 2017; Rosenblum et al., 2020).

The eDarkTrends NER also identified the amount of substances listed for sale in terms of weight (i.e., total amount in gram or milliliter) and quantity (i.e., total number of items). Weight and units of dosage were transformed into grams ( $\mathrm{g}$ ) for powder and base form, in milliliter (ml) for liquid substances. For pharmaceutical fentanyl or counterfeit pharmaceutical products (e.g., films, patches, pills) as well as for oxycodone pills pressed with fentanyl, the amount was calculated based on the number of items (quantity) rather than the weight to ensure that listings with a large number of items that contain a very small amount of active ingredient (e.g., patches with micrograms of fentanyl) would not distort average price calculations. Duplicate listings were not removed from the analysis for two main reasons: a) DreamMarket listings did not offer the possibility for vendors to display their stock or "quantity left" such as in some other markets (e.g., EmpireMarket); 2) new listings were added or removed over time suggesting that listings were regularly updated and did not accumulate over time such as in

Table 1

Categorization of opioid listings.

\begin{tabular}{|c|c|}
\hline Category & Sub-category \\
\hline Heroin & Heroin \\
\hline "Synthetic Heroin" & Synthetic Heroin \\
\hline Pharmaceutical Fentanyl & Pharmaceutical Fentanyl (e.g., Duragesic, Sublimaze, fentanyl transdermal system) \\
\hline Non-Pharmaceutical Fentanyl & 1)Non-pharmaceutical fentanyl; 2) Oxycodone pills with fentanyl \\
\hline Fentanyl Analogs & $\begin{array}{l}\text { 1) 3-allylfentanyl; 2) 3-methylbutyrfentanyl; 3) 3-methylfentanyl; 4) 3-methylmethoxyacetylfentanyl; 5) 3-methylthiofentanyl; 6) 3m- } \\
\text { furanylfentanyl, 7) 3m-methoxylacetylfentanyl; 8) 4anpp; 9) 4appp; 10) 4-fluoroisobutyrfentanyl; 11) 4-flurobutyrfentanyl; 12) 4- } \\
\text { methoxymethylfentanyl; 13) 4npp; 14) 4-phenylfentanyl; 15) acetylfentanyl; 16) acrylfentanyl; 17) acryloylfentanyl; 18) alfentanyl; 19) } \\
\text { alphamethylthiofentanyl; 20) amethylacetylfentanyl; 21) appp; 22) benzylfentanyl; 23) betahydroxyfentanyl; 24) betahydroxythiofentanyl; 25) } \\
\text { betamethylfentanyl; 25) butryfentanyl; 27) butyrfentanyl; 28) butyrfluorofentanyl; 29) butyrfuranylfentanyl; 30) carfentanil; 31) } \\
\text { crotonylfentanyl; 32) etorphine; 33) etorphinecartanil; 34) fluorofentanyl; 35) furanylfentanyl; 36) isobutyrfentanyl; 37) lofentanyl; 38) } \\
\text { methoxyacetylfentanyl; 39) methylfentanyl; 40) mirfentanyl; 41) nmethylcarfentanil; 42) ocfentanil; 43) ohmefentanyl; 44) } \\
\text { orthomethylfuranylfentanyl; 45) paraflurofentanyl; 46) pentafentanyl; 47) R-30,490; 48) remifentanil; 49) sufentanil; 50) } \\
\text { tetrahydrofuranylfentanyl; 51) thiofentanyl }\end{array}$ \\
\hline Other novel synthetic opioids & $\begin{array}{l}\text { 1) U-50,488; 2) U-47,700; 3) U-49,900; 4) U-48,800; 5) MT-45; 6) AH-7921; 7) W-18; 8) MPF-47700; 9) U-4TDP; 10) isopropyl-U-47,700; 11) } \\
\text { MP-47700; 12) U-47v700; 13) U-47,931e; 14) FS-33; 15) U-57,700; 16) AP-237; 17) W-15 }\end{array}$ \\
\hline Other Pharmaceutical opioids & $\begin{array}{l}\text { 1) buprenorphine; 2) codeine; 3) hydrocodone; 4) hydromorphone; 5) loperamide; 6) methadone; 7) morphine; 8) naloxone; 9) oxycodone; 10) } \\
\text { oxymorphone; 11) tramadol }\end{array}$ \\
\hline Kratom & Kratom \\
\hline Opium & Opium \\
\hline
\end{tabular}


Table 2

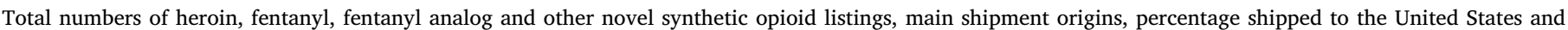
associated unique vendor counts on DreamMarket cryptomarket during the eDarkTrends data collection period (22nd of March 2018 to 26th of January 2019).

\begin{tabular}{|c|c|c|c|c|c|}
\hline Substances & $\begin{array}{l}\text { Number of Listings } \\
\text { (TOTAL } \mathrm{N}=95,011 \text { ) }\end{array}$ & $\begin{array}{l}\text { Percent of all } \\
\text { listings }\end{array}$ & $\begin{array}{l}\text { Main countries of origin (\% of } \\
\text { listings) }\end{array}$ & $\begin{array}{l}\text { \% shipping to the } \\
\text { U.S.A. }\end{array}$ & $\begin{array}{l}\text { Number of Unique } \\
\text { Vendors }\end{array}$ \\
\hline Heroin & 52,510 & $55.27 \%$ & $\begin{array}{l}\text { U.S.A., } 27.0 \% \text {; Germany, } 22.1 \% \text {; } \\
\text { U.K., } 13.8 \%\end{array}$ & $80.00 \%$ & 532 \\
\hline "Synthetic Heroin" & 1031 & $1.09 \%$ & Canada, 97.9 \%; U.S.A., $2.1 \%$ & $100 \%$ & 30 \\
\hline Pharmaceutical Fentanyl* & 301 & $0.32 \%$ & $\begin{array}{l}\text { Italy, } 32.4 \% \text {; Netherlands, } 20.7 \% \text {; } \\
\text { Germany, } 19.6 \%\end{array}$ & $59.90 \%$ & 36 \\
\hline \multicolumn{6}{|l|}{ Non-Pharmaceutical Fentanyl } \\
\hline Non-Pharmaceutical Fentanyl & 395 & $0.42 \%$ & $\begin{array}{l}\text { Australia, } 38.3 \% \text {; U.S.A., } 29.5 \% \text {; } \\
\text { Canada, } 21.8 \%\end{array}$ & $93.40 \%$ & 33 \\
\hline Oxycodone Pills with Fentanyl* & 123 & $0.13 \%$ & U.S.A., $100 \%$ & $100 \%$ & 5 \\
\hline \multicolumn{6}{|l|}{ Fentanyl Analogs } \\
\hline Furanylfentanyl (Fu-F) & 217 & $0.23 \%$ & $\begin{array}{l}\text { Slovakia, } 66.1 \% \text {; Germany, } 21.0 \% \text {; } \\
\text { India, } 1.9 \%\end{array}$ & $94.00 \%$ & 5 \\
\hline Methoxyacetyl-fentanyl (MAF) & 103 & $0.11 \%$ & $\begin{array}{l}\text { China, } 39.1 \% \text {; India, } 32.6 \% \text {; U.S.A., } \\
26.1 \%\end{array}$ & $93.20 \%$ & 12 \\
\hline 4-Fluoroisobutyr-fentanyl (4-FIBF) & 101 & $0.11 \%$ & China, $63.6 \%$; India, $36.4 \%$ & $100 \%$ & 4 \\
\hline Carfentanil & 45 & $0.05 \%$ & $\begin{array}{l}\text { China, } 52.5 \% \text {; U.S.A., } 40.0 \% \text {; } \\
\text { Germany, } 7.5 \%\end{array}$ & $100 \%$ & 7 \\
\hline Butyrfluorofentanyl & 35 & $0.04 \%$ & China, $100 \%$ & $85.70 \%$ & 2 \\
\hline Precursors (4-ANPP, 4-APPP, APPP) & 20 & $0.02 \%$ & China, $100 \%$ & $100 \%$ & 1 \\
\hline Acetylfentanyl & 13 & $0.01 \%$ & U.K., $100 \%$ & $100 \%$ & 1 \\
\hline 4-Phenylfentanyl & 12 & $0.01 \%$ & ND & $100 \%$ & 1 \\
\hline $\begin{array}{l}\text { 3-Methylmethoxy-acetylfentanyl (3- } \\
\text { MMAF) }\end{array}$ & 10 & $0.01 \%$ & China, $100 \%$ & $100 \%$ & 1 \\
\hline Butyrfentanyl (Butyrylfentanyl) & 6 & $0.01 \%$ & ND & $33.30 \%$ & 2 \\
\hline 4-Methoxymethyl-fentanyl (R-30490) & 4 & $0.00 \%$ & China, $66 \%$; India, $33 \%$ & $100 \%$ & 2 \\
\hline Orthomethyl-furanylfentanyl (o-Me-Fu-F) & 2 & $0.00 \%$ & U.S.A., $100 \%$ & $100 \%$ & 1 \\
\hline \multicolumn{6}{|l|}{ Other Novel Synthetic Opioids } \\
\hline $\mathrm{U}-48,800$ & 224 & $0.24 \%$ & China, $64.3 \%$; Australia, $3.1 \%$ & $93.70 \%$ & 13 \\
\hline $\mathrm{U}-50,488$ & 106 & $0.11 \%$ & China, $100 \%$ & $100 \%$ & 3 \\
\hline U-4TDP & 100 & $0.11 \%$ & China, $100 \%$ & $100 \%$ & 1 \\
\hline $\mathrm{U}-47,700$ & 84 & $0.09 \%$ & $\begin{array}{l}\text { China, } 79.8 \% \text {; India, } 3.6 \text { \%; U.S.A., } \\
2.4 \%\end{array}$ & $100 \%$ & 6 \\
\hline Isopropyl-U-47,700 & 59 & $0.06 \%$ & China, $8.5 \%$ & $100 \%$ & 1 \\
\hline MPF-47,700 & 42 & $0.04 \%$ & China, $100 \%$ & $100 \%$ & 1 \\
\hline MP-47,700 & 37 & $0.04 \%$ & China, $100 \%$ & $100 \%$ & 1 \\
\hline $\mathrm{U}-49,900$ & 9 & $0.01 \%$ & China, $66.6 \%$ & $66.60 \%$ & 2 \\
\hline U-58,800 & 6 & $0.01 \%$ & China, $100 \%$ & $100 \%$ & 1 \\
\hline $\mathrm{U}-47 \mathrm{v} 700$ & 4 & $<0.01 \%$ & China, $100 \%$ & $100 \%$ & 1 \\
\hline AP-237 & 3 & $<0.01 \%$ & China, $100 \%$ & $100 \%$ & 2 \\
\hline Bromadoline (U-47931e) & 3 & $<0.01 \%$ & China, $100 \%$ & $100 \%$ & 1 \\
\hline XIX-18 & 2 & $<0.01 \%$ & China, $100 \%$ & $100 \%$ & 1 \\
\hline Etorphinecartanil & 1 & $<0.01 \%$ & China, $100 \%$ & $100 \%$ & 1 \\
\hline FS-33 & 1 & $<0.01 \%$ & ND & $100 \%$ & 1 \\
\hline U-45,500 & 1 & $<0.01 \%$ & ND & $100 \%$ & 1 \\
\hline W-18 & 1 & $<0.01 \%$ & China, $100 \%$ & $100 \%$ & 1 \\
\hline
\end{tabular}

Alphabay. Instead, we have assumed that vendors posting similar listings were advertising a specific weight/quantity of a product they had in stock several times.

Prices were converted from Bitcoin (BTC) to U.S. dollars according to the BTC-\$US conversion rate on the day DreamMarket was crawled. Listings offering free drug samples were excluded when calculating the average price. Average prices (U.S. \$ per gram) were calculated separately for retail and wholesale-level amounts. The weight limit between "retail" and "wholesale" quantities was arbitrarily set to $5 \mathrm{~g}$ (20 items for listing not in powder or liquid form) to acknowledge the potency of novel synthetic opioids. Shipment origins and destinations were grouped by country. Manual checks have been performed to remove inconsistent data and outliers to prevent potential distortions in the calculations of averages. Listings displaying several countries (e.g., "FRANCE BELGIUM HOLLAND GERMANY") or imprecise/inexistent/ ambivalent countries of origins (e.g., "North Pole," "The White House") were excluded from the analysis.

\subsection{Reliability assessment of the named entity recognition algorithm}

A random subsample of 555 listings ( $0.5 \%$ of all listings) was selected for manual assessment of the accuracy of the eDarkTrends Named Entity Recognition (NER) algorithm. The first author manually classified each of the selected listings $(n=555)$ to identify the class and sub-class of the listed substance, its weight, form and quantity. The results of the manual classification were compared to the results of automated classification performed by the eDarkTrends NER algorithm. The accuracy assessment indicates that the NER algorithm was able to correctly identified $99.3 \%$ of substances, $98.9 \%$ of class of substances, $96.9 \%$ of weight, $98.2 \%$ of form and $91.0 \%$ of quantity contained in the listings from the random subsample.

\section{Results}

\subsection{Collected data}

110,892 listings were collected from DreamMarket through 26 crawling sessions between the 22nd of March 2018 and 26st of January 2019. $85.7 \%(95,011 / 110,892)$ of all collected listings were identified as related to opioids, and the remaining $14.3 \%(15,881 / 110,892)$ did not contain elements that the NER identified as belonging to the opioid class of substances (i.e., non-opioid drugs, special customer order or "tip 
jar" for vendor). These listings were excluded from further analysis. On average, 4,107 listings related to opioids were collected at each crawl.

\subsection{Availability of novel synthetic opioids}

Out of 95,011 opioid-related listings, $3.3 \%(3,101 / 95,011)$ were for novel synthetic opioids. In comparison, heroin was identified in $55.2 \%$ $(52,510 / 95,011)$ of all opioid-related listings, and there were 1,945 heroin-related listings per each crawl, on average.

Both pharmaceutical fentanyl $(301 / 95,011)$ and non-pharmaceutical fentanyl and analogs $(1,086 / 95,011)$ were advertised on DreamMarket representing $1.5 \%(1,387 / 95,011)$ of all opioid-related listings and accounting for $44.7 \%(1,387 / 3,101)$ of all novel synthetic opioid-related listings. During the study period, an average of $2.8 \mathrm{~kg}$ of fentanyl-type substances were listed for sale at each time point of data collection. In addition, there were an average of 2,495 non-pharmaceutical oxycodone pills pressed with fentanyl available for purchase at each time point when data were collected. The information about the amount of fentanyl added to these pills was specified only by one vendor, in a total of 7 listings (out of 123), and was equal to $150 \mu \mathrm{g}$.

"Synthetic heroin" was the most frequent type of other novel synthetic opioid advertised accounting for $1.1 \%(1,031 / 95,011)$ of all opioid-related listings, and representing $33.2 \%(1,031 / 3,101)$ of all novel synthetic opioid-related listings. On average, there was about 1.1 $\mathrm{kg}$ of synthetic heroin listed for sale at each data point. Remaining other novel synthetic opioids products (e.g., W-18, U-47,700) were identified in $0.7 \%(683 / 95,011)$ of all opioid-related listings. They comprised about $22 \%(683 / 3,101)$ of all novel synthetic opioid-related listings, with an average of $6.1 \mathrm{~kg}$ offered for sale at each data point (Table 2).

Eleven fentanyl analogs (acetylfentanyl, burtyrfentanyl, butyrfluorofentanyl, carfentanil, furanylfentanyl, methoxyacetylfentanyl, orthomethylfuranylfentanyl, 3-methylmethoxyacetyl-fentanyl, 4-fluorobutyrfentanyl, 4-methoxymethylfentanyl (R-30,490) and 4-phenylfentanyl) and three precursor chemicals (advertised as 4-ANPP, 4APPP and APPP) were identified over the data collection period. Among fentanyl analogs, furanylfentanyl was the most commonly advertised $(217 / 568)$ with an average of $2.3 \mathrm{~kg}$ offered for sale at each data point, followed by methoxyacetyl-fentanyl (103/568), and 4-fluoroisobutyrfentanyl (101/568). There was a total of 45 listings (out of a total of 568 fentanyl analog listings) for carfentanil, an extremely potent fentanyl analog that is also used in veterinary medicine as a large animal tranquilizer. On average, there were $548.7 \mathrm{~g}$ of carfentanil available for purchase during the data collection period (Table 2).

The fentanyl ban implemented by DreamMarket on the 20th of May 2018 had considerable effect on the availability of non-pharmaceutical fentanyl and fentanyl analog listings. Before the ban, there was an average of 144.8 listings (and average weight of $11.1 \mathrm{~kg}$ ) for nonpharmaceutical fentanyl or fentanyl analogs at each time period of data collection. After the ban, the average number of listings of these substances at each data collection period declined to 8.9, and the average total available weight decreased to $233.8 \mathrm{~g}$.

Regarding other novel synthetic opioids, 17 different substances were identified in a total of 683 listings. U-48,800 was the most frequent substance listed among them $(32.8 \%, 224 / 683)$ with an average of 1,845.4 $\mathrm{g}$ available for purchase at each date of data collection. Eight other novel synthetic opioids (U-47v700, AP-237, bromadoline (U47,931e), XIX-18, etorphinecartanil, FS-33, U-45,500 and W-18) were identified at only one data point.

Overall, the eDarkTrends NER identified 14 substances (namely, 3methylmethoxyacetylfentanyl (3-MMAF), 4-ANPP, 4-FIBF, acetylfentanyl, butyrylfentanyl, carfentanil, despropionyl-p-fluorofentanyl, fentanyl, furanylfentanyl, isopropyl-U-47,700, methoxyacetylfentanyl, U-47,700, U-48,800, U-49,900) of the 34 novel synthetic opioids listed by the Special Testing and Research Laboratory of the Drug Enforcement Agency (DEA, 2018a,2018b, 2019) and the National Medical Services (NMS Labs, 2019a). The remaining 16 novel synthetic opioids, namely, 4-methoxy-methylfentanyl, butyrfluorofentanyl, 4APPP, APPP, 4-phenylfentanyl, orthomethylfuranyfentanyl (o-ME-FuF), U-50,488, U-4TDP, MPF-47,700, MP-47,700, U-58,800, U-47v700, bromadoline (U-47931e), XIX-18, etorphinecartanil, FS-33, U-45,500 and $\mathrm{W}-18$, haven't been identified in the seizures/evidences tests run by the DEA nor in the forensic tests run by the NMS Labs at the time this article was written. AP-237 was identified by NMS labs in September 2019 (NMS Labs, 2019b).

\subsection{Prices}

The average price of a gram of non-pharmaceutical fentanyl was U.S. $\$ 1,470.4$ for listings offering less than $5 \mathrm{~g}$ and U.S. $\$ 139.5$ for listings offering $5 \mathrm{~g}$ or more. Notably, carfentanil was advertised for an average price of U.S.\$2,311.8 per gram for retail-level amounts and an average price of U.S.\$101.0 per gram for wholesale-level amounts. Furanylfentanyl (Fu-F), the most common fentanyl analog appearing on DreamMarket, was advertised for an average price of U.S.\$243.1 per gram for retail listings and an average price of U.S.\$26.5 per gram for wholesale listings. For other novel synthetic opioids, U-48,800 was advertised on average U.S.\$48.4 per gram for retail-level amounts and U.S.\$14.2 per gram for listings offering wholesale-level amounts. U47,700 was offered for an average price of U.S.\$100.3 per gram for retail listings and an average price of U.S.\$19.7 per gram for wholesale listings. Finally, "synthetic heroin" was advertised for an average price of U.S.\$121.2 per gram for retail listings and an average price of U.S. $\$ 69.5$ per gram for wholesale listings. For comparison, the average price for a gram of heroin was U.S.\$206.5 for retail-level and U.S.\$32.3 for wholesale-level amounts (Table 3).

\subsection{Shipment origins and destinations}

More than half $(53.7 \%, 51,018 / 95,011)$ of all opioid-related listings displayed country-level geolocation information indicating shipment origin ("shipping from"). Out of all fentanyl-related listings (both pharmaceutical and non-pharmaceutical), $66.9 \%(928 / 1,387)$ displayed country-level geolocation information. Notably, the United States was the main country of origin from where vendors indicated they were selling non-pharmaceutical oxycodone pills mixed with fentanyl with $100 \%(116 / 116)$ of the listings displaying geolocation information at the country level (116 out of the total 123 listings). Furthermore, non-pharmaceutical fentanyl was mainly advertised by unique vendor names indicating they were shipping from Australia (38.3\%, 114/298), followed by the United States (29.5\%, 88/298), and Canada (21.8\%,65/298).

Most of the fentanyl analogs were predominantly advertised as shipped from China, except acetylfentanyl (U.K, $100 \%$, 13/13), orthomethylfuranylfentanyl (U.S., $100 \%, 2 / 2$ ) and furanylfentanyl (Slovakia, 66.1 \%, 41/62; Germany, $21.0 \%, 13 / 62$ ). China was also the main country of origin for carfentanil with $52.5 \%$ (21/40) of listings with geolocation at the country level, followed by the U.S. (40.0\%, 16/ 40 ) and Germany $(7.5 \%, 3 / 40)$. Furthermore, China (97.2\%) was the main shipment origin for other novel synthetic opioids advertised on DreamMarket. Other novel synthetic opioid listings were posted by 24 vendors with 20 out 24 of them based in China. Only 8 vendors posted 10 listings or more, with three of them posting $82.9 \%$ of all other novel synthetic opioid-related posts. Finally, the majority of the "synthetic heroin" listings with country-level geolocation information were advertised as shipped from Canada (97.9\%, 939/959).

More than $80 \%$ of listings advertising novel synthetic opioids on DreamMarket (with the exceptions of pharmaceutical fentanyl, butyrfentanyl, and U-49,900) could be shipped to the United States (Table 2). 
Table 3

Average total available weights, numbers or wholesale and retail listings and average prices for heroin, fentanyl, fentanyl analogs and other novel synthetic opioids advertised on DreamMarket during the eDarkTrends data collection period (22nd of March 2018 to 26th of January 2019). * Difference between Retail and Wholesale was set to 20 items.

\begin{tabular}{|c|c|c|c|c|c|}
\hline \multirow[t]{2}{*}{ Substances } & \multirow{2}{*}{$\begin{array}{l}\text { Average total weights available at each data } \\
\text { collection time point - grams (min-max) }\end{array}$} & \multicolumn{2}{|l|}{ Retail Amounts $(<=5 \mathrm{~g})$} & \multicolumn{2}{|l|}{ Wholesale Amounts ( $>5 \mathrm{~g}$ ) } \\
\hline & & $\begin{array}{l}\text { Average price in US\$ per } \\
\text { gram (min-max) }\end{array}$ & $\begin{array}{l}\text { Number of } \\
\text { listings }\end{array}$ & $\begin{array}{l}\text { Average price in US\$ per } \\
\text { gram (min-max) }\end{array}$ & $\begin{array}{l}\text { Number of } \\
\text { listings }\end{array}$ \\
\hline Heroin & $954.8(601-2,267)$ & $206.5(28.3-1,881)$ & 24,758 & $32.3(0.2-170.2)$ & 27,752 \\
\hline "Synthetic Heroin" & $1,149.3(25.9-4,216.8)$ & $121.2(0.1-701.9)$ & 643 & $69.5(7.0-129.9)$ & 388 \\
\hline Pharmaceutical Fentanyl* & $117.2(5-277)$ & $91.1(17.2-307.5)$ & 257 & $75.7(30.0-109.5)$ & 44 \\
\hline \multicolumn{6}{|l|}{ Non-Pharmaceutical Fentanyl } \\
\hline Non-Pharmaceutical Fentanyl & $266.4(0.3-1,998.8)$ & $1470.4(216.7-4,371.9)$ & 274 & $139.5(4.3-1,637.3)$ & 57 \\
\hline Oxycodone Pills with Fentanyl* & $2,494.7(25-5,250)$ & $6.4(1.0-11.9)$ & 6 & $1.1(1.0-12.8)$ & 117 \\
\hline \multicolumn{6}{|l|}{ Fentanyl Analogs } \\
\hline Furanylfentanyl (Fu-F) & $2,296.6(1-6,716.3)$ & $243.1(13.5-1,442.5)$ & 111 & $26.5(4.5-151.6)$ & 106 \\
\hline Methoxyacetyl-fentanyl (MAF) & $722.3(<0.01-2,594.2)$ & $194.1(28.0-606.3)$ & 26 & $40.0(5.2-165.8)$ & 77 \\
\hline 4-Fluoroisobutyr-fentanyl (4-FIBF) & $3,265.7(540.7-3,955.7)$ & $181.8(17.7-516.5)$ & 47 & $18.3(6.6-182.5)$ & 54 \\
\hline Carfentanil & $548.7(0.05-3,551.5)$ & $2,311.8(182.5-4,221.9)$ & 25 & $101.0(26.0-231.6)$ & 20 \\
\hline Butyrfluorofentanyl & $1977(1,935-2,040)$ & $33.3(32.2-34.3)$ & 2 & $12.3(6.1-28.9)$ & 33 \\
\hline $\begin{array}{l}\text { Precursors (4-ANPP, 4-APPP, } \\
\text { APPP) }\end{array}$ & $643.7(100-900)$ & ND & 0 & $5.4(3.5-7.6)$ & 20 \\
\hline Acetylfentanyl & $1.7(0-1.7)$ & $134.1(108.6-159.7)$ & 1 & ND & 0 \\
\hline 4-Phenylfentanyl & $1(0.5-1.5)$ & $1,746.8(1,694.2-1,799)$ & 1 & ND & 0 \\
\hline $\begin{array}{l}\text { 3-Methylmethoxy-acetylfentanyl } \\
\text { (3-MMAF) }\end{array}$ & $510(510-510)$ & ND & 0 & $17.8(3.9-34.9)$ & 10 \\
\hline Butyrfentanyl (Butyrylfentanyl) & $110.1(110-110.3)$ & $651.2(579.0-723.4)$ & 2 & $23.0(20.5-25.5)$ & 4 \\
\hline $\begin{array}{l}\text { 4-Methoxymethyl-fentanyl (R- } \\
\text { 30490) }\end{array}$ & $195(195-195)$ & ND & 0 & $22.9(20.8-25.1)$ & 4 \\
\hline $\begin{array}{l}\text { Orthomethyl-furanylfentanyl (o- } \\
\text { Me-Fu-F) }\end{array}$ & $<0.01$ & $95.2(75.2-115.2)$ & 2 & ND & 0 \\
\hline \multicolumn{6}{|l|}{ Other Novel Synthetic Opioids } \\
\hline $\mathrm{U}-48,800$ & $1,845.4(10-3,715)$ & $48.4(27.5-193)$ & 35 & $14.2(4.7-122.3)$ & 189 \\
\hline $\mathrm{U}-50,488$ & $1,447(10-1,910)$ & $35.0(19.2-52.2)$ & 4 & $10.8(6.1-32.1)$ & 102 \\
\hline U-4TDP & $1,460(260-1,910)$ & ND & 0 & $10.6(6.1-22.7)$ & 100 \\
\hline $\mathrm{U}-47,700$ & $540(0.06-1,947)$ & $100.3(43.9-149.0)$ & 27 & $19.7(5.9-53.0)$ & 57 \\
\hline Isopropyl-U-47,700 & $1,425(885-1,941)$ & $86.4(43.1-151.9)$ & 12 & $16.2(6.6-36.0)$ & 47 \\
\hline MPF-47,700 & $760(10-1,912)$ & $25.7(24.6-26.7)$ & 5 & $13.1(6.2-24.3)$ & 37 \\
\hline MP- 47,700 & $1,268(652-1,902)$ & $36.5(34.7-38.2)$ & 6 & $8.6(6.2-12.8)$ & 31 \\
\hline $\mathrm{U}-49,900$ & $22.5(10-110)$ & ND & 0 & $29.5(23.2-45.8)$ & 9 \\
\hline U-58,800 & $1,125(1,125-1,125)$ & ND & 0 & $8.2(6.2-11.7)$ & 6 \\
\hline U-47v700 & $1,160(1,160-1,160)$ & ND & 0 & $17.1(7.3-31.2)$ & 4 \\
\hline AP-237 & $10(10-10)$ & ND & 0 & 41.8 & 3 \\
\hline Bromadoline (U-47931e) & $112.5(100-125)$ & ND & 0 & $15.3(7.2-16.6)$ & 3 \\
\hline XIX-18 & $35(35-35)$ & 129.9 & 1 & 96.6 & 1 \\
\hline Etorphinecartanil & 1 & $1,989.50$ & 1 & ND & 0 \\
\hline FS-33 & 1 & ND & ND & ND & ND \\
\hline U-45,500 & 500 & ND & 0 & 9.1 & 1 \\
\hline W-18 & 25 & ND & 0 & 22.9 & 1 \\
\hline
\end{tabular}

\subsection{Shipment origins by wholesale and retail level amounts}

In terms of the weights advertised for non-pharmaceutical fentanyl and analogs (fentanyl precursors excluded), $34.0 \%(363 / 1,066)$ of listings were advertising wholesale quantities (> 5 g). $52.3 \%$ (190/ 363 ) of them displayed geolocation information at the country level: $47.4 \%(90 / 190)$ advertised as shipped from China, $14.7 \%(28 / 190)$ from India, $12.6 \%$ (24/190) from Australia, and $10.5 \%$ (20/190) from the United States. Among these 363 "wholesale" listings, 150 advertised quantities equal to or greater than $100 \mathrm{~g}$ with $53.3 \%(80 / 150)$ of them displaying geolocation at the country-level. China was indicated as the shipment origins for $67.5 \%$ (54/80) of these listings, followed by India with $20.0 \%(16 / 80)$, Slovakia with $7.5 \%(6 / 80)$ and the United States with $1.3 \%(1 / 80)$. Among the 569 non-pharmaceutical fentanyl and analogs (fentanyl precursors excluded) advertising less than $5 \mathrm{~g}$ of substance, $59.4 \%(338 / 569)$ displayed geolocation at the country level. $39.9 \%(135 / 338)$ of these listings advertised shipment from the U.S, $24.3 \%(82 / 338)$ from Australia, and $18.3 \%(62 / 338)$ from Canada. Only $2.1 \%(7 / 338)$ were advertised as shipped from China.

\section{Discussion}

Our study presents a detailed description of the type, average amount and shipment origin of novel synthetic opioids advertised on one cryptomarket (DreamMarket) over a 10-months period (March 2018-January 2019). It is one of the first studies to describe and quantify the types, amounts, available weights, prices and shipment origins and destination of fentanyl, fentanyl analogs and other novel synthetic opioid products sold on the darknet. Fentanyl, fentanyl analogs, "synthetic heroin" and other novel synthetic opioid substances represent only $3.3 \%$ of all opioid listings advertised on DreamMarket from March 2018 to January 2019. Although novel synthetic opioids constitute a small fraction of the overall illicit opioid market on the darknet, the potency of these opioids make the amount needed for one dose smaller compared to other opioids (Pardo et al., 2019). It also decreases the quantity needed to be sent by mail, lowering the chance for shipment to be detected and seized by customs or law enforcement agents (Baum, 2017; O'Connor, 2017).

Furthermore, our data suggest that as listed on DreamMarket, the average wholesale price per gram of fentanyl analogs (except carfentanil and methoxyacetylfentanyl) and U-47,700 analogs (e.g., U48,800 , MPF-47,700, U-58,800) were lower compared to the average 
wholesale prices for a gram of heroin, making these novel substances a more potent and profitable alternative to heroin for drug dealers. Interestingly, most of the U-47,700 analogs, such as U-48,800, were generally sold for lower prices than fentanyl-type drugs, which could be, at least, partially explained by the lower potency of these substances, compared to fentanyl-type drugs: for example, U-47,700 is considered to be 7.5 stronger than morphine, compared to fentanyl considered to be 50-100 times more potent than morphine (Mohr et al., 2016). Moreover, the large discount existing between retail and wholesale quantities (up to 23 times for carfentanil and 17 times for non-pharmaceutical fentanyl) indicates substantial incentives for profitability of retail-level activities and distribution.

DreamMarket advertised a large amount and variety of opioids with more than 4000 opioid-related posts advertising as much as 71 different types of opioid products on a regular basis. During the data collection period, 33 substances classified as novel synthetic opioids were identified by the eDarkTrends platform, and at the time of writing this paper, 17 of them have not yet been identified by the DEA or NMS in the United States. However, novel synthetic opioid AP-237 was first detected by the eDarkTrends NER in January 2019. It was subsequently identified by NMS labs, but nearly nine month later, in September 2019 (NMS Labs, 2019b). This example highlights the utility of the eDarkTrends platform and cryptomarket data in general for timely identification and effective surveillance of emerging substance use trends.

Our data suggest that China was the main country of origin of wholesale quantities of novel synthetic opioids advertised on DreamMarket. However, $52.6 \%$ of all fentanyl-type drug listings (precursors and pharmaceutical fentanyl excluded) that offered retaillevel amounts were posted by unique vendor names who indicated they were shipping from the U.S. and Canada. This highlights the role of cryptomarkets in contributing to within-country retail-level novel synthetic opioids market transactions (Aldridge and Décary-Hétu, 2016a,b). Despite the recent crackdown attempts by the Chinese government on fentanyl and fentanyl analog production (Associated Press, 2019; Myers, 2019), the existence of this network of retail sellers located in the U.S. and Canada calls for an increased surveillance of postal packages within and between Canada and the United States (Malaea, 2019). In addition, the case of "synthetic heroin" requires further investigation: while representing $44.7 \%$ of the total novel synthetic opioids advertised on DreamMarket, its exact chemical composition remains unknown, potentially increasing the risk for opioid users who purchase this type of substance to suffer severe adverse consequences. This is of crucial importance considering that "synthetic heroin" appeared to be mainly advertised as shipped from Canada (97.9\%). Similar to the U.S., Canada has also experienced notable increases in novel synthetic opioid availability and associated adverse consequences (Pardo et al., 2019). In 2018, novel synthetic opioids were identified in more than $50 \%$ of all opioid-related drug samples seized by law enforcement in Canada (Drug Analysis Service, 2019). In addition, 78 \% of all overdose deaths that occurred in Canada between January September 2019, involved fentanyl and/or fentanyl analogs (Special Advisory Committee on the Epidemic of Opioid Overdoses, 2020).

Limitations are noted. First, due to the illegal nature and the volatility of cryptomarkets, crawling cryptomarkets represent a unique challenge for automated data collection as the research team was unable to crawl DreamMarket during some time periods due to Distributed Denial of Service (DDoS) attacks or because the cryptomarket was under security maintenance. Second, numbers of vendors were calculated based on the sum of vendor "unique names" displayed in each advertisement, which might not accurately describe the exact number of vendors as one vendor could sell various products using different aliases on one cryptomarket, possibly explaining the large number of vendors identified during data collection. Third, this research describes the amounts of novel synthetic opioids available through the listings, and information on the actual amounts of substances sold on DreamMarket remain unknown. Forth, shipment origin data were only partial and, in some cases, may not represent the real origin of shipment, which, in turn, could have contributed to bias in the shipment origin calculation. Finally, the weight used to differentiate retail from wholesale quantities was set arbitrarily and requires further investigations to allow a more precise quantification.

\section{Conclusions}

Our study provides new insights into the role of the darknet in the availability of non-pharmaceutical fentanyl, fentanyl analogs and other novel synthetic opioids. Although focusing on one market (DreamMarket) over a 10-months period, data indicate a persistent availability of both retail and wholesale quantities of non-pharmaceutical fentanyl, fentanyl analogs, and other synthetic opioids, drugs that are causing devastating increases in unintentional drug overdose deaths in the U.S. (Peterson et al., 2016; Scholl et al., 2019) and in Canada (Hung et al., 2019). The exact role of the darknet in novel synthetic opioid availability continues to remain undocumented because there is no certainty regarding what quantities are being shipped where and for what purpose-for individual or small network use or for larger scale redistribution. Important future work includes comparing the availability and shipment origin of substances advertised on the darknet with the national seizure data to estimate the impact of cryptomarkets on substance accessibility at the national level. Additional research is needed to monitor novel synthetic opioid sales on the darknet and to further understand how purchased items are actually being used, either through the analysis of drug forum discussions and/or through online surveys and interviews with customers and/or sellers (Barratt et al., 2016). Furthermore, information about new detections of synthetic opioids on cryptomarkets could also be communicated to darknet market customers via existing community forums, alongside appropriate harm-reduction advice. Another possibility would be to contact cryptomarket administrators when information contained in listing descriptions of new substances are erroneous and/or misleading potentially leading to adverse consequences for users. This is particularly true in the case of "synthetic heroin," where buyers are almost completely unaware of what they are purchasing.

\section{Role of funding source}

This study was supported by the United States of America National Institute on Drug Abuse (NIDA), Grant No. R21 DA-044518-02 (Daniulaityte, PI; Lamy, PI; Sheth, PI). The funding source had no further role in the study design, in the collection, analysis and interpretation of the data, in the writing of the report, or in the decision to submit the paper for publication.

\section{CRediT authorship contribution statement}

Francois R. Lamy: Conceptualization, Data curation, Formal analysis, Funding acquisition, Investigation, Methodology, Project administration, Software, Supervision, Validation, Writing - original draft, Writing - review \& editing. Raminta Daniulaityte: Conceptualization, Formal analysis, Funding acquisition, Investigation, Methodology, Project administration, Resources, Supervision, Validation, Writing original draft, Writing - review \& editing. Monica J. Barratt: Conceptualization, Funding acquisition, Investigation, Methodology, Writing - original draft, Writing - review \& editing. Usha Lokala: Data curation, Methodology, Software, Writing - original draft. Amit Sheth: Conceptualization, Funding acquisition, Project administration, Resources, Supervision, Writing - original draft. Robert G. Carlson: Conceptualization, Formal analysis, Funding acquisition, Investigation, Supervision, Validation, Writing - original draft, Writing - review \& editing. 


\section{Declaration of Competing Interest}

\section{No conflict declared.}

\section{References}

Aldridge, J., Décary-Hétu, D., 2016a. Hidden wholesale: the drug diffusing capacity of online drug cryptomarkets. Int. J. Drug Policy 35, 7-15.

Aldridge, J., Décary-Hétu, D., 2016b. Cryptomarkets and the Future of Illicit Drug Markets. Internet and drug markets, EMCDDA insights, Publications Office of the European Union, Luxembourg, pp. 23-30.

Associated Press, 2019. China to Regulate All Fentanyl Drugs, Keeping Promise to Trump. Los Angeles Times.

Ball, M., Broadhurst, R., Trivedi, H., 2019. How Much Fentanyl Is Available on the Darknet? Statistical Bulletin 18. Australian Institute of Criminology, Canberra, pp. 1-6.

Barratt, M.J., Aldridge, J., 2016. Everything you always wanted to know about drug cryptomarkets* (*but were afraid to ask). Int. J. Drug Policy 35, 1-6.

Barratt, M.J., Lenton, S., Maddox, A., Allen, M., 2016. 'What if you live on top of a bakery and you like cakes?'-Drug use and harm trajectories before, during and after the emergence of silk road. Int. J. Drug Policy 35, 50-57.

Barratt, M.J., Aldridge, J., Maddox, A., 2018. Dark Web. The SAGE Encyclopedia of the Internet, pp. 1-4.

Baum, R.J., 2017. Letter to Congress: Response to Questions Concerning Fentanyl. Office of National Drug Control Policy, Washington DC.

Baumann, M.H., Majumdar, S., Le Rouzic, V., Hunkele, A., Uprety, R., Huang, X.P., Xu, J., Roth, B.L., Pan, Y.-X., Pasternak, G.W., 2018. Pharmacological characterization of novel synthetic opioids (NSO) found in the recreational drug marketplace. Neuropharmacology 134, 101-107.

Bird, S., Klein, E., Loper, E., 2009. Natural Language Processing with Python. O’Reilly Media, Inc.

Cameron, D., Smith, G.A., Daniulaityte, R., Sheth, A.P., Dave, D., Chen, L., Anand, G., Carlson, R., Watkins, K.Z., Falck, R., 2013. PREDOSE: a semantic web platform for drug abuse epidemiology using social media. J. Biomed. Inform. 46, 985-997.

Carlson, R.G., Nahhas, R.W., Martins, S.S., Daniulaityte, R., 2016. Predictors of transition to heroin use among initially non-opioid dependent illicit pharmaceutical opioid users: a natural history study. Drug Alcohol Depend. 160, 127-134.

Castillo-Carniglia, A., Ponicki, W.R., Gaidus, A., Gruenewald, P.J., Marshall, B.D.L., Fink, D.S., Martins, S.S., Rivera-Aguirre, A., Wintemute, G.J., Cerdá, M., 2019. Prescription drug monitoring programs and opioid overdoses: exploring sources of heterogeneity. Epidemiology 30, 212-220.

Ciccarone, D., 2019. The triple wave epidemic: supply and demand drivers of the US opioid overdose crisis. Int. J. Drug Policy 71, 183-188.

Ciccarone, D., Ondocsin, J., Mars, S.G., 2017. Heroin uncertainties: exploring users' perceptions of fentanyl-adulterated and-substituted 'heroin'. Int. J. Drug Policy 46, $146-155$.

Cicero, T.J., Ellis, M.S., Surratt, H.L., Kurtz, S.P., 2014. The changing face of heroin use in the United States: a retrospective analysis of the past 50 years. JAMA Psychiatry 71, $821-826$

Compton, W.M., Volkow, N.D., 2006. Abuse of prescription drugs and the risk of addiction. Drug Alcohol Depend. 83 (Suppl 1), S4-7.

Daniulaityte, R., Carlson, R., Brigham, G., Cameron, D., Sheth, A., 2015. "Sub is a weird drug:" A web-based study of lay attitudes about use of buprenorphine to self-treat opioid withdrawal symptoms. Am. J. Addict. 24, 403-409.

Daniulaityte, R., Juhascik, M.P., Strayer, K.E., Sizemore, I.E., Harshbarger, K.E., Antonides, H.M., Carlson, R.R., 2017a. Overdose deaths related to fentanyl and its analogs - Ohio, january-february 2017. Morb. Mortal. Rep. 66, 904-908.

Daniulaityte, R., Lamy, F.R., Smith, G.A., Nahhas, R.W., Carlson, R.G., Thirunarayan, K., Martins, S.S., Boyer, E.W., Sheth, A., 2017b. "Retweet to pass the blunt": analyzing geographic and content features of cannabis-related tweeting across the United States. J. Stud. Alcohol Drugs 78, 910-915.

Daniulaityte, R., Juhascik, M.P., Strayer, K.E., Sizemore, I.E., Zatreh, M., Nahhas, R.W., Harshbarger, K.E., Antonides, H.M., Martins, S.S., Carlson, R.R., 2019. Trends in fentanyl and fentanyl analogue-related overdose deaths - montgomery County, Ohio, 2015-2017. Drug Alcohol Depend. 198, 116-120.

DEA, 2018a. Emerging Threat Report, Annual Report 2018. U.S. Drug Enforcement Administration (DEA).

DEA, 2018b. Fentanyl Remains the Most Significant Synthetic Opioid Threat and Poses the Greatest Threat to the Opioid User Market in the United States. U.S. Drug Enforcement Administration (DEA).

DEA, 2019. Emerging Threat Report, First Quarter 2019. U.S. Drug Enforcement Administration (DEA).

Dolliver, D.S., 2015. Evaluating drug trafficking on the Tor network: silk Road 2, the sequel. Int. J. Drug Policy 26, 1113-1123.

Dolliver, D.S., Kuhns, J.B., 2016. The presence of new psychoactive substances in a tor network marketplace environment. J. Psychoact. Drugs 48, 321-329.

Drug Analysis Service, 2019. Drug Analysis Service: Summary Report of Samples Analyzed in 2018. Government of Canada.

EMCDDA, 2019. European Drug Report 2019: Trends and Developments. Publications Office of the European Union, Luxembourg.
Europol, EMCDDA, 2017. Drugs and the Darknet: Perspectives for Enforcement, Research and Policy. Publications Office of the European Union, Luxembourg.

Hall, A.J., Logan, J.E., Toblin, R.L., Kaplan, J.A., Kraner, J.C., Bixler, D., Crosby, A.E., Paulozzi, L.J., 2008. Patterns of abuse among unintentional pharmaceutical overdose fatalities. JAMA 300, 2613-2620.

Hedegaard, H., Warner, M., Miniño, A.M., 2018. Drug Overdose Deaths in the United States, 1999-2017. US Department of Health and Human Services, Centers for Disease Control and Prevention, NCHS Data Brief, pp. 273.

Hung, O., Stewart, R.D., Malpas, G., Phipps, S., Hung, D., 2019. Managing the opioid epidemic: back to the basics with resuscitation. CJEM 21, 175-176.

Jones, C.M., Einstein, E.B., Compton, W.M., 2018. Changes in synthetic opioid involvement in drug overdose deaths in the United States, 2010-2016. JAMA 319, 1819-1821.

Kruithof, K., Aldridge, J., Décary-Hétu, D., Sim, M., Dujso, E., Hoorens, S., 2016a. Internet-facilitated Drugs Trade: an Analysis of the Size, Scope and the Role of the Netherlands. R. Corporation. Santa Monica, CA, RAND Corporation.

Kruithof, K., Aldridge, J., Hétu, D.D., Sim, M., Dujso, E., Hoorens, S., 2016b. The Role of the "dark Web" in the Trade of Illicit Drugs. RAND Corporation, WODC, Ministerie van Veilgheid en Justitie.

Lamy, F.R., Daniulaityte, R., Nahhas, R.W., Barratt, M.J., Smith, A.G., Sheth, A., Martins, S.S., Boyer, E.W., Carlson, R.G., 2017. Increased in synthetic cannabinoids-related harms: results from a longitudinal web-based content analysis. Int. J. Drug Policy 44 121-129.

Lokala, U., Lamy, F.R., Daniulaityte, R., Sheth, A., Nahhas, R.W., Roden, J.I., Yadav, S. Carlson, R.G., 2019. Global trends, local harms: availability of fentanyl-type drugs on the darkweb and accidental overdoses in Ohio. Comput. Math. Organ. Theory 25, 48-59.

Madore, P.H., 2019. Dream Market Shuts Down: Has the DEA Claimed Another Darknet Victim? CCN.com Retrieved 26/03/2019, from. https://www.ccn.com/dreammarket-shuts-down-has-the-dea-claimed-another-darknet-victim.

Malaea, M., 2019. Montana Border Patrol Reports Amount of Fentanyl Seized Has Gone Up By 36 Times Since 2014. Retrieved 20/12/2019, from. Newsweek. https:// www.ccn.com/dream-market-shuts-down-has-the-dea-claimed-another-darknetvictim.

Mars, S.G., Bourgois, P., Karandinos, G., Montero, F., Ciccarone, D., 2014. "Every 'never'I ever said came true": transitions from opioid pills to heroin injecting. Int. J. Drug Policy 25, 257-266.

Martin, M., Hecker, J., Clark, R., Frye, J., Jehle, D., Lucid, E.J., Harchelroad, F., 1991. China White epidemic: an eastern United States emergency department experience. Ann. Emerg. Med. 20, 158-164.

Mohr, A.L., Friscia, M., Papsun, D., Kacinko, S.L., Buzby, D., Logan, B.K., 2016. Analysis of novel synthetic opioids U-47700, U-50488 and furanyl fentanyl by LC-MS/MS in postmortem casework. J. Anal. Toxicol. 40, 709-717.

Musen, M.A., 2015. The Protégé project: a look back and a look forward. AI matters. Association of Computing Machinery Specific Interest Group in Artificial Intelligence 1. https://doi.org/10.1145/2557001.25757003.

Myers, S.L., 2019. China Cracks Down on Fentanyl. But Is It Enough to End the U.S Epidemic? The New York Times.

NMS Labs, 2019a. Designer Opioids (2018 Scope) (Qualitative).

NMS Labs, 2019b. AP-237. Retrieved from:. . https://www.npsdiscovery.org/wpcontent/uploads/2019/09/AP-237_091619_NMSLabs_Report.pdf.

O'Connor, S., 2017. Fentanyl: China's deadly export to the United States. US-China Economic and Security Review Commission, Staff Research Report.

Pardo, B., Taylor, J., Caulkins, J.P., Kilmer, B., Reuter, P., Stein, B.D., 2019. The Future of Fentanyl and Other Synthetic Opioids. RAND Corporation.

Paulozzi, L.J., Budnitz, D.S., Xi, Y., 2006. Increasing deaths from opioid analgesics in the United States. Pharmacoepidem. Dr. S. 15, 618-627.

Peterson, A.B., Gladden, R.M., Delcher, C., Spies, E., Garcia-Williams, A., Wang, Y. Halpin, J., Zibbell, J., McCarty, C.L., DeFiore-Hyrmer, J., 2016. Increases in fentanylrelated overdose deaths_Florida and Ohio, 2013-2015. Morb. Mortal. Rep. 65, 844-849.

Rosenblum, D., Unick, J., Ciccarone, D., 2020. The rapidly changing US illicit drug market and the potential for an improved early warning system: evidence from Ohio drug crime labs. Drug Alcohol Depend. 208, 107779.

Scholl, L., Seth, P., Kariisa, M., Wilson, N., Baldwin, G., 2019. Drug and opioid-involved overdose deaths-United States, 2013-2017. Morb. Mortal. Rep. 67, 1419.

Special Advisory Committee on the Epidemic of Opioid Overdoses, 2020. Opioid-related Harms in Canada. Public Health Agency of Canada, Ottawa. https://health-infobase. canada.ca/substance-related-harms/opioids.

Unick, G.J., Rosenblum, D., Mars, S., Ciccarone, D., 2013. Intertwined epidemics: national demographic trends in hospitalizations for heroin- and opioid-related overdoses, 1993-2009. PLoS One 8, e54496.

Unick, G., Rosenblum, D., Mars, S., Ciccarone, D., 2014. The relationship between us heroin market dynamics and heroin-related overdose, 1992-2008. Addiction 109, 1889-1898.

Van Buskirk, J., Naicker, S., Roxburgh, A., Bruno, R., Burns, L., 2016. Who sells what? Country specific differences in substance availability on the Agora cryptomarket. Int. J. Drug Policy 35, 16-23.

Van Rossum, G., 1990. Python (langage).

Van Zee, A., 2009. The promotion and marketing of oxycontin: commercial triumph, public health tragedy. Am. J. Public Health 99, 221-227. 